\title{
Sickle cell retinopathy. A focused review
}

\author{
Maram E. A. Abdalla Elsayed ${ }^{1} \cdot$ Marco Mura $^{2} \cdot$ Hassan Al Dhibi ${ }^{2} \cdot$ Silvana Schellini $^{3} \cdot$ Rizwan Malik $^{4} \cdot \operatorname{Igor~Kozak~}^{5} \cdot$ \\ Patrik Schatz ${ }^{2,6}$ (1)
}

Received: 11 December 2018 / Revised: 23 February 2019 / Accepted: 10 March 2019 / Published online: 20 March 2019

(C) The Author(s) 2019

\begin{abstract}
Purpose To provide a focused review of sickle cell retinopathy in the light of recent advances in the pathogenesis, multimodal retinal imaging, management of the condition, and migration trends, which may lead to increased prevalence of the condition in the Western world.

Methods Non-systematic focused literature review.

Results Sickle retinopathy results from aggregation of abnormal hemoglobin in the red blood cells in the retinal microcirculation, leading to reduced deformability of the red blood cells, stagnant blood flow in the retinal precapillary arterioles, thrombosis, and ischemia. This may be precipitated by hypoxia, acidosis, and hyperosmolarity. Sickle retinopathy may result in sight threatening complications, such as paracentral middle maculopathy or sequelae of proliferative retinopathy, such as vitreous hemorrhage and retinal detachment. New imaging modalities, such as wide-field imaging and optical coherence tomography angiography, have revealed the microstructural features of sickle retinopathy, enabling earlier diagnosis. The vascular growth factor ANGPTL-4 has recently been identified as a potential mediator of progression to proliferative retinopathy and may represent a possible therapeutic target. Laser therapy should be considered for proliferative retinopathy in order to prevent visual loss; however, the evidence is not very strong. With recent development of wide-field imaging, targeted laser to ischemic retina may prove to be beneficial. Exact control of intraoperative intraocular pressure, including valved trocar vitrectomy systems, may improve the outcomes of vitreoretinal surgery for complications, such as vitreous hemorrhage and retinal detachment. Stem cell transplantation and gene therapy are potentially curative treatments, which may prevent retinopathy.

Conclusions There is lack of evidence regarding the optimal management of sickle retinopathy. Further study is needed to determine if recent progress in the understanding of the pathophysiology and diagnosis of sickle retinopathy may translate into improved management and outcome.
\end{abstract}

Keywords Hemoglobin S $\cdot$ Hemoglobin C $\cdot$ Ischemia $\cdot$ Neovascularization $\cdot$ Panretinal photocoagulation $\cdot$ Sickle cell retinopathy

Electronic supplementary material The online version of this article (https://doi.org/10.1007/s00417-019-04294-2) contains supplementary material, which is available to authorized users.

Patrik Schatz

pschatz@kkesh.med.sa

Jeddah Eye Hospital, Jeddah, Kingdom of Saudi Arabia

2 Vitreoretinal Division, King Khaled Eye Specialist Hospital, Al-Oruba Street, 7191, Riyadh 11462, Kingdom of Saudi Arabia

3 Oculoplasty Division, King Khaled Eye Specialist Hospital, Riyadh, Kingdom of Saudi Arabia

4 Glaucoma Division, King Khaled Eye Specialist Hospital, Riyadh, Kingdom of Saudi Arabia

5 Moorfields Eye Hospital Centre, Abu Dhabi, United Arab Emirates

6 Department of Ophthalmology, Clinical Sciences, Skane University Hospital, Lund University, Lund, Sweden

\section{Introduction and epidemiology}

Current geopolitical scenario and ongoing waves of immigration may lead to new challenges for practicing ophthalmologists, requiring an increased awareness to diagnose and ability to manage sickle cell disease (SCD) and sickle cell retinopathy. For example, in 2016, 863.3 thousand citizens of nonmember countries residing in an EU Member State acquired EU citizenship (Eurostat statistics explained; https://ec. europa.eu/eurostat/statistics-explained/index.php/Migration and_migrant_population_statistics\#Acquisitions_of citizenship:_EU_Member_States_granted_citizenship_to_ almost 1_million_persons in 2016). These new EU citizens were mainly from Africa (30\% of the total number of citizenships) and Asia (21\%), areas where hemoglobinopathies are highly prevalent (http://www.who. 
int/genomics/public/Maphaemoglobin.pdf). Furthermore, the above data for EU citizenships for 2016 corresponded to a $19 \%$ increase with respect to 2015 . In addition, there may be an even larger and growing population of immigrants from these areas in the EU who do not have any EU citizenship and thus would not be listed above. Thus, the prevalence of SCD and sickle cell retinopathy would be expected to increase in the Western world, which in turn may have implications for health economics and for training of local ophthalmologist who may not be familiar with these conditions. For example, assuming a prevalence of up to $3 \%$ of SCD as may occur in endemic areas $[1,2]$ and a population of two million recent EU immigrants from such areas would mean that up to $0.03 \times$ $2,000,000=60,000$ individuals may be at risk of developing sickle retinopathy.

\section{Classification of retinopathy}

Organs commonly involved in SCD are the kidneys, skeleton, lungs, liver, and skin. All ocular and orbital structures can be affected by microvascular occlusions from SCD. However, the major cause of vision loss is proliferative sickle cell retinopathy (PSR) (Fig. 1). Goldberg's classification is still used to grade retinopathy severity (stages $\mathrm{I}-\mathrm{V}$ ) of the retinopathy [3], where stages I-II represent non-proliferative sickle retinopathy (NPSR). Similar to other retinal vascular disorders, such as retinopathy of prematurity and diabetic retinopathy, it is based on clinically significant alterations of the retinal vasculature with disease progression:

I. Peripheral arterial occlusion. This is caused by aggregation of pathological hemoglobin within erythrocytes under conditions, such as hypoxia, acidosis, and hyperosmolarity, leading to decreased deformability of erythrocytes, stagnant flow, and thrombosis.

II. Peripheral arteriovenous anastomoses (hairpin loop). This represents the initial stage of the vascular remodeling that takes place as a response to the circulatory disturbances that occur in stage I.

III. Neovascularization (sea fan). This occurs at the posterior border of non-perfusion, possibly as a result of release of angiogenic factors from the peripheral ischemic retina. A white sea fan appearance can result from auto-infarction of the neovasculature. Stage III (PSR) was subsequently subdivided, based on a prospective clinical trial of observation (35 eyes) versus retinal photocoagulation (38 eyes) [4], considering sea fan size, hemorrhage, fibrosis,
Fig. 1 Proliferative sickle retinopathy. By high-performance liquid chromatography (HPLC), isoelectric focusing, and citrate agar electrophoresis at $\mathrm{pH} 6.2$, two abnormal hemoglobins are detectable, indicating heterozygosity for $\mathrm{HbS}$ and $\mathrm{HbC}$. Upper panel, from left to right: early and late frame wide-field fluorescein angiography and wide-field pseudocolor imaging show peripheral non-perfusion and neovascularization and lasered retina with regressed neovascularization. Middle and lower panel: optical coherence tomography shows bilateral temporal macular thinning compatible with previous bilateral acute middle maculopathy

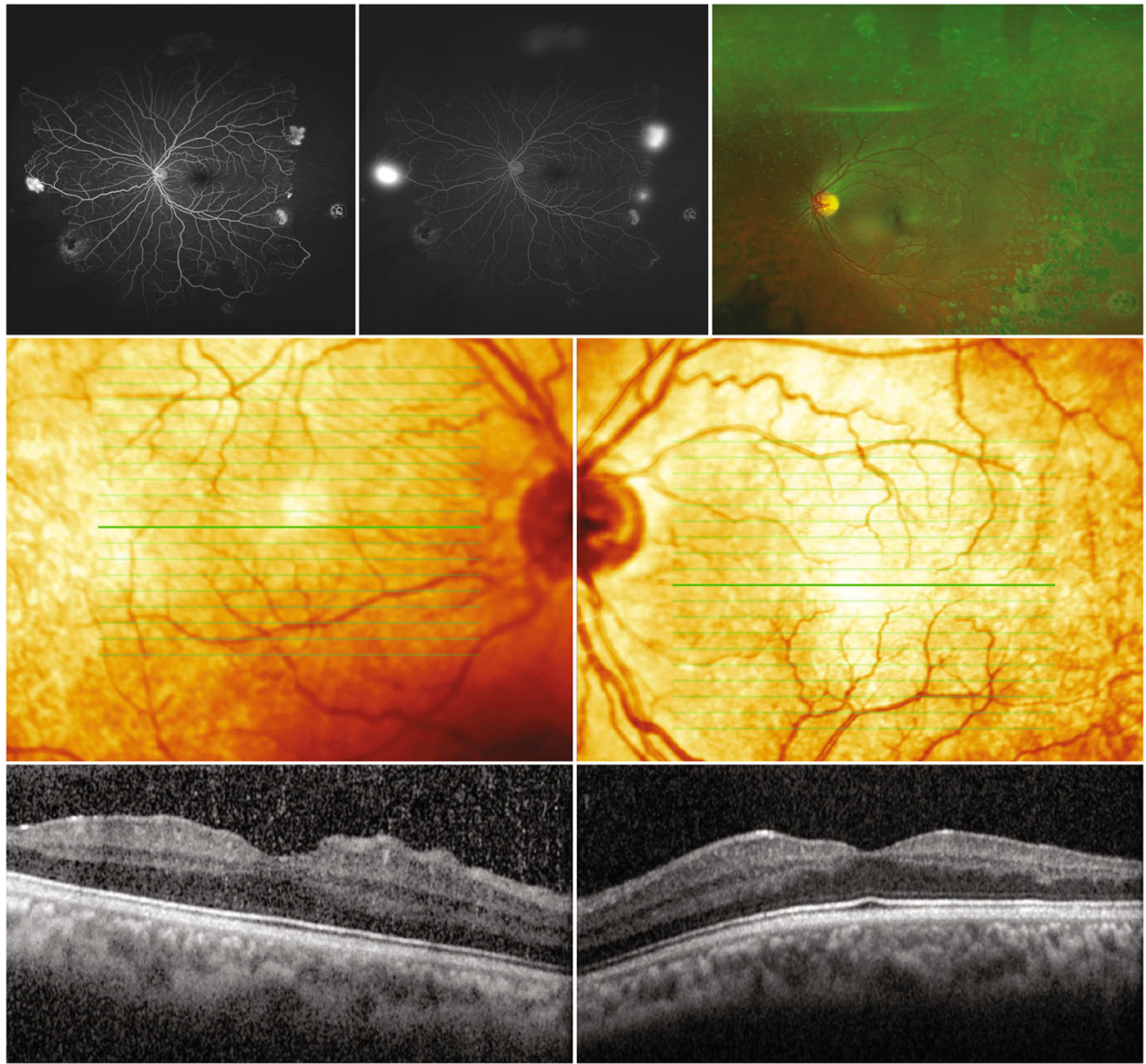


and visibility of vessels into grade A: flat sea fan with leakage $<1$ disc area; grade B: elevated sea fan with hemorrhage; grade $\mathrm{C}$ : elevated sea fan with partial fibrosis; grade D: complete sea fan fibrosis without well demarcated vessels; grade E: complete sea fan fibrosis with well demarcated vessels [4]. Nine complications (13\%) were observed, which only occurred in untreated eyes with elevated sea fan and hemorrhage (grade B) or complete fibrosed sea fan with well-defined vessels (grade E). The clinical course did not differ between treated and untreated groups concerning flat sea fan $<1$ disc area (grade A) or elevated sea fan with partial fibrosis (grade $\mathrm{C})$, suggesting that patients with grade $\mathrm{A}$ or $\mathrm{C}$ new sea fan classification may be observed initially [4].

IV. Vitreous hemorrhage (VH). This is commonly a result of bleeding from the neovascularizations.

V. Tractional retinal detachment (TRD) and rhegmatogenous retinal detachment (RRD). This results from degenerative changes in the vitreous over the leaking neovascularizations, leading to membrane formation and traction.

\section{Hemoglobin mutations and structural changes}

The HbVar database (http://globin.bx.psu.edu/hbvar, access date October 1, 2017) of hemoglobin ( $\mathrm{Hb})$ describes over 1600 variants of hemoglobin molecules. The wild-type alleles are called HBA and HBB, which are transcribed to $\alpha$-globin and $\beta$-globin, respectively. In adults, hemoglobin normally consists of two subunits of $\beta$-globin and two subunits of $\alpha$ globin. Each of these protein subunits is bound to an ironcontaining heme, each containing an iron molecule in its center that can bind to one oxygen molecule. A single nucleotide mutation (GAG to GTG) causes the substitution of valine for glutamic acid at the sixth position of the $\beta$-globin chain in $\mathrm{HBB}$, resulting in hemoglobin $\mathrm{S}(\mathrm{HbS})$. In the homozygous condition (HbSS), this mutation causes sickle cell anemia (SCA), which was frequently lethal before the advent of modern medicine, such as transfusion medicine. In the heterozygous condition (HbAS), the mutation results in a milder sickle cell trait (SCT) phenotype. A GAG to AAG mutation causes the substitution of lysine for glutamic acid, resulting in the $\mathrm{HbC}$ allele. Homozygous absence or decreased synthesis of the $\beta$ chain from certain mutations in HBB is referred to as $\beta$ thalassemia. When present in a compound heterozygous mode with the $\mathrm{HbS}$ allele, this is referred to as hemoglobin sicklebeta thalassemias (HbSthal). These are the most common genotypes that may lead to SCD. Further described $\mathrm{HbS}$ variants include $\mathrm{HbSD}, \mathrm{HbSE}$, and $\mathrm{HbSO}$ (https://ghr.nlm.nih.gov/ gene/HBB\#conditions, accessed on 20190220).
HbSC subjects are believed to be at higher risk of developing PSR, compared with HbSS and HbSthal patients [5-11] (Table 1). The reason for this is unknown, and assessment may be biased because of differences in mortality rates and systemic treatment, such as transfusion or hydroxycarbamide [12]. However, one possible explanation could be higher hematocrit in subjects with HbSC compared with those with HbSS, leading to a higher tendency towards stagnant blood flow and thus thrombosis formation in the retinal precapillary arterioles [13]. Fox et al. observed 35 patients ( 40 eyes) with HbSS and 112 patients (114 eyes) with $\mathrm{HbSC}$ over a mean of 4-5 years [14]. In both genotypes, progression of PSR was most frequent between ages 20 and 39 years. Comparison of hematological indices, such as fetal hemoglobin ( $\mathrm{HbF})$ levels, in 33 HbSC patients with progression and the 17 with regression, revealed no significant differences [14].

\section{Non-proliferative sickle cell retinopathy (stages I-II)}

NPSR is commonly observed in patients with HbSS genotype. Clinical findings include peripheral retinal vascular closure/ anastomoses, salmon-patch hemorrhages, iridescent spots, and black sunbursts (where the latter two may be chronic manifestation of salmon-patch hemorrhages). Central retinal changes consist of arteriovenous tortuosity, enlargement of the foveal avascular zone (FAZ), and arterial occlusions. Collectively, these are manifestations of stage I-II sickle cell retinopathy. Bilateral macular occlusive events may present with binasal field defects [15]. Electrophysiology indicates a selective early involvement of the inner retina in HbSS patients, which may be compatible with vascular occlusions in the superficial and deep capillary plexi in the inner retina [16].

\section{Proliferative sickle cell retinopathy (stages III-V)}

PSR is more frequently manifested in patients with $\mathrm{HbSC}$ than in other genotypes, and some degree of visual loss occurs in 5-20\% of PSR eyes [11, 17, 18] (Table 1). PSR is associated with thinning of temporal macular retinal layers caused by acute paracentral middle maculopathy, which results from occlusions of the superficial and deep capillary plexi [19, 20]. Peripheral retinal vascular occlusions cause tissue ischemia and release of angiogenic mediators that promote retinal neovascularization. The hallmark in PSR patients is the sea fan configuration that occurs when the neovascularization grows anteriorly from the vascularized to avascular retina (Fig. 1). These structures have a high propensity to regress (20$60 \%)$ by autoinfarction $[11,16]$. However, they may also lead to VH or TRD. 


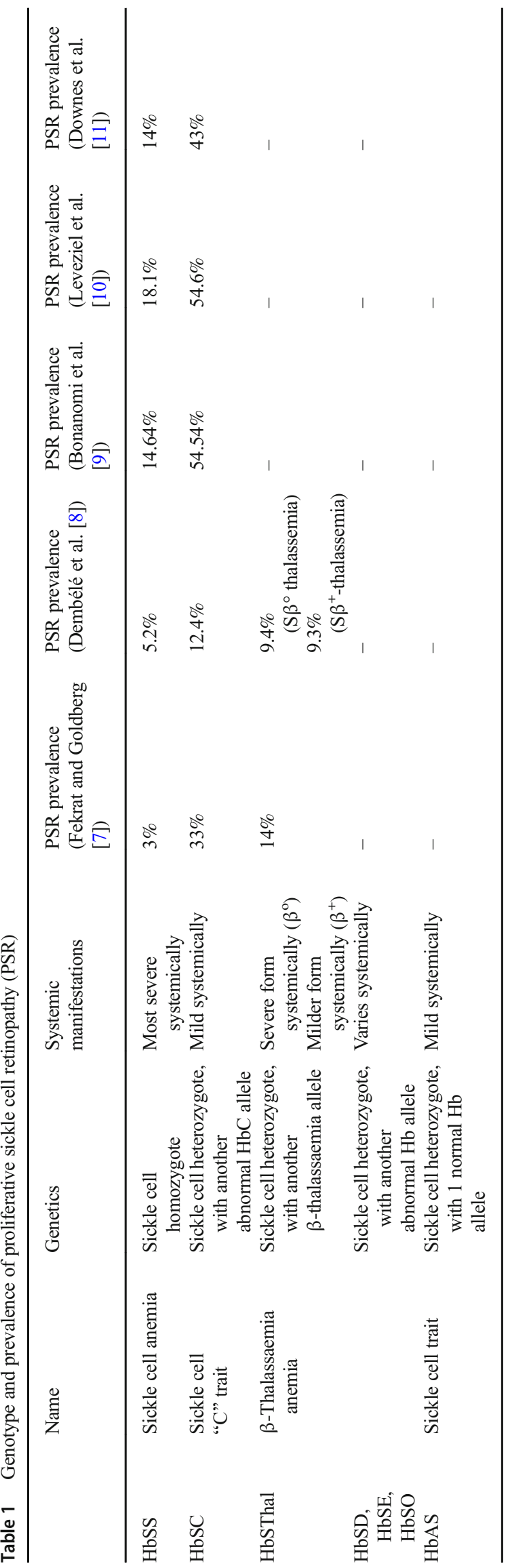

\section{Orbital manifestations of SCD}

Children with SCD may develop uni- or bilateral infarctions of the orbital bones, mainly affecting the great wing of sphenoid, with pain, headache, fever, visual acuity changes, periorbital edema, proptosis, and limited extraocular motility [21]. Bone and/or bone marrow infarction results in sterile inflammation and sub-periosteal hematoma. Exudative retinal detachment can be present in SCD-induced orbital bone infarction as a result of orbito-ocular inflammation. There may be optic nerve compression [22]. The differential diagnosis includes periorbital or orbital cellulitis, orbital abscess, or allergic reaction. Orbital wall infarction is diagnosed by computerized tomography or magnetic resonance imaging [23]. Doppler velocimetry can demonstrate elevated arterial vascular resistance in the orbit [24]. Treatment includes intravenous hydration, pain control, steroids, or even surgery when orbital compartment syndrome is present [23]. However, clinically relevant orbital manifestations of SCD are considered to be rare. On the other hand, these may be underdiagnosed considering the ischemic nature with a tendency of spontaneous improvement.

\section{Glaucoma}

Hyphaema, ghost cells from VH, or neovascularization of the angle may result in secondary glaucoma. Sickle cells may give rise to a more intense elevation of the intraocular pressure (IOP) than non-sickle cells because of reduced deformability during the passage through the trabecular meshwork, and glaucoma secondary to hyphaema may be more refractory to medical treatment [25]. The threshold for IOP lowering treatment (medical as well as surgical if needed) is low as the optic disc and the central retinal artery are thought to have a higher susceptibility to damage, due to impaired microcirculation. Oral carbonic anhydrase inhibitors, especially acetazolamide, should not be used regularly, because these may cause dehydration and acidosis, leading to increased sickling of erythrocytes [13].

\section{Genetic and systemic risk factors of sickle cell retinopathy and proliferative sickle cell retinopathy}

Malaria is or was highly prevalent in areas where SCD is common, and it is believed that heterozygosity for the sickle cell allele may confer malarial resistance and hence, a selective advantage [26]. As for other recessive disorders, consanguineous marriage increases the risk of SCD in endemic areas.

Despite the less serious systemic consequences of $\mathrm{HbSC}$ subjects, they are believed to be at higher risk of developing 
PSR, compared with HbSS and HbSthal patients $[5,6]$. The reason for this is unknown, and assessment may be biased because of differences in systemic treatment, such as transfusion or hydroxycarbamide or different mortality rates [12]. One possible explanation could be higher hematocrit in subjects with $\mathrm{HbSC}$ compared with those with $\mathrm{HbSS}$, leading to a higher tendency towards stagnant blood flow and thus thrombosis formation in the retinal precapillary arterioles [13]. On the other hand, there seems to be no link between rheological factors (plasma and serum viscosity, whole blood viscosity, and erythrocyte filterability) and the development of PSR $[14,27,28]$.

With increasing prevalence of type 2 diabetes mellitus (DM) worldwide, a large cohort of people may have concurrent DM and SCT, considering that the prevalence of SCT may approach $20 \%$ in endemic areas [1]. It would be reasonable to hypothesize that coexisting SCT and DM may increase the risk of microvascular complications. However, Al Harbi et al. conducted a retrospective analysis of the rate of PDR and/or diabetic macular edema in 100 patients with SCT and $\mathrm{DM}$ and an equal number of age-matched controls with DM but no SCT [29]. The rate of PDR and/or diabetic macular edema was significantly higher in the controls (95\%) than in patients with SCT $(58 \%, p<0.001)$ [29]. Thus, the proangiogenic molecules that play a role in disease progression may differ between SCD and DM. On the other hand, TRD was more frequent in patients with SCT than in controls ( $26 \%$ vs $11 \%, p=0.006$ ) [29]. One possibility is that temporal macular ischemia, similar to that seen after acute middle maculopathy in PSR, may contribute to the formation of TRD in patients with SCT and DM.

Age is considered as one of the risk factors of progression to PSR, and the risk of PSR below 10 years of age is very rare. Talbot et al. conducted serial examinations in 389 children aged 5-13 years with SCD. Peripheral retinal vessel closure was present in approximately $50 \%$ of children with SS and SC genotypes at age 6 years and increased to affect $90 \%$ of children by age 12 years. Proliferative retinopathy occurred only once in an 8-year-old boy with SC disease, despite 592 patient years of observation [30]. A retrospective analysis of 258 children with SCD identified 54 children with Sickle cell retinopathy [31]. Pain crisis, male gender, and splenic sequestration were clinical risk factors that were associated with sickle cell retinopathy in these pediatric patients [31]. Of the 54 children with sickle retinopathy, $11(4.3 \%)$ had PSR, with a mean age at diagnosis of 12.7 years (range 10-17 years).

PSR was associated with older age ( $>35$ years) in a London cohort of 189 patients with SCD [32]. Visual impairment was related to the presence of PSR; however, it was not related to $\mathrm{Hb}$ genotype [32]. The association between age and progression towards PSR was further corroborated in a recent retrospective study of 296 patients with SCD, where male gender and older age were associated with PSR [33].
Sickle cell retinopathy has phenotypic variability even among individuals with the same genotype. A crosssectional study in a Brazilian SCA cohort showed that IL-6$597 \mathrm{G}>\mathrm{A}$ is associated with a higher likelihood of retinopathy [34]. A Greek study determined that the endothelial nitric oxide (NO) synthase T786C polymorphism was more common in $\mathrm{HbSS}$ and $\mathrm{HbS} \beta 0$ patients with retinopathy in comparison with the G894T polymorphism [35]. Environmental factors may confound these studies. For example, Mehta et al. described a patient with SCT who developed PSR after mild ocular blunt trauma [36]. The reported prevalence of PSR in various genotypes is summarized in Table 1.

\section{Diagnosis}

Cation-exchange high-performance liquid chromatography (HPLC), in conjunction with electrophoresis, is the main diagnostic method [37].

Molecular genetic diagnosis has been described for prenatal and neonatal screening [38, 39].

Diagnosis of retinopathy is based on typical clinical findings in the presence of a history of SCD or positive laboratory findings as described above.

\section{Differential diagnoses}

A wide spectrum of diseases that result in either macular ischemia, or peripheral retinal neovascularization, should be considered in the differential diagnosis [40-45] (Table 2). On the other hand, sickle retinopathy should be considered as a differential diagnosis in retinal vascular disease. A prior history of SCD helps rule out many other conditions, although it is possible for some other conditions to occur simultaneously with NPSR/PSR.

\section{Advances in sickle cell retinopathy ocular biology}

Identifying molecules associated with PSR development may help in their use as therapeutic targets. Angiopoietin-like 4 (ANGPTL4) has been detected in neovascular tissue and in the ischemic inner retina in PSR, but not in control eyes. Its presence has been well documented in other vasoproliferative ocular condition like diabetes retinopathy, retinal vein occlusion, and age-related macular degeneration, and only recently, it was established in PSR [46]. Elevated expression of ANGPTL4 has also been observed in the aqueous and vitreous of PSR patients compared with controls [46], suggesting that it may contribute to PSR development (Fig. 2). Knowledge regarding the origin and retinal distribution of 
Table 2 Differential diagnosis of sickle cell retinopathy

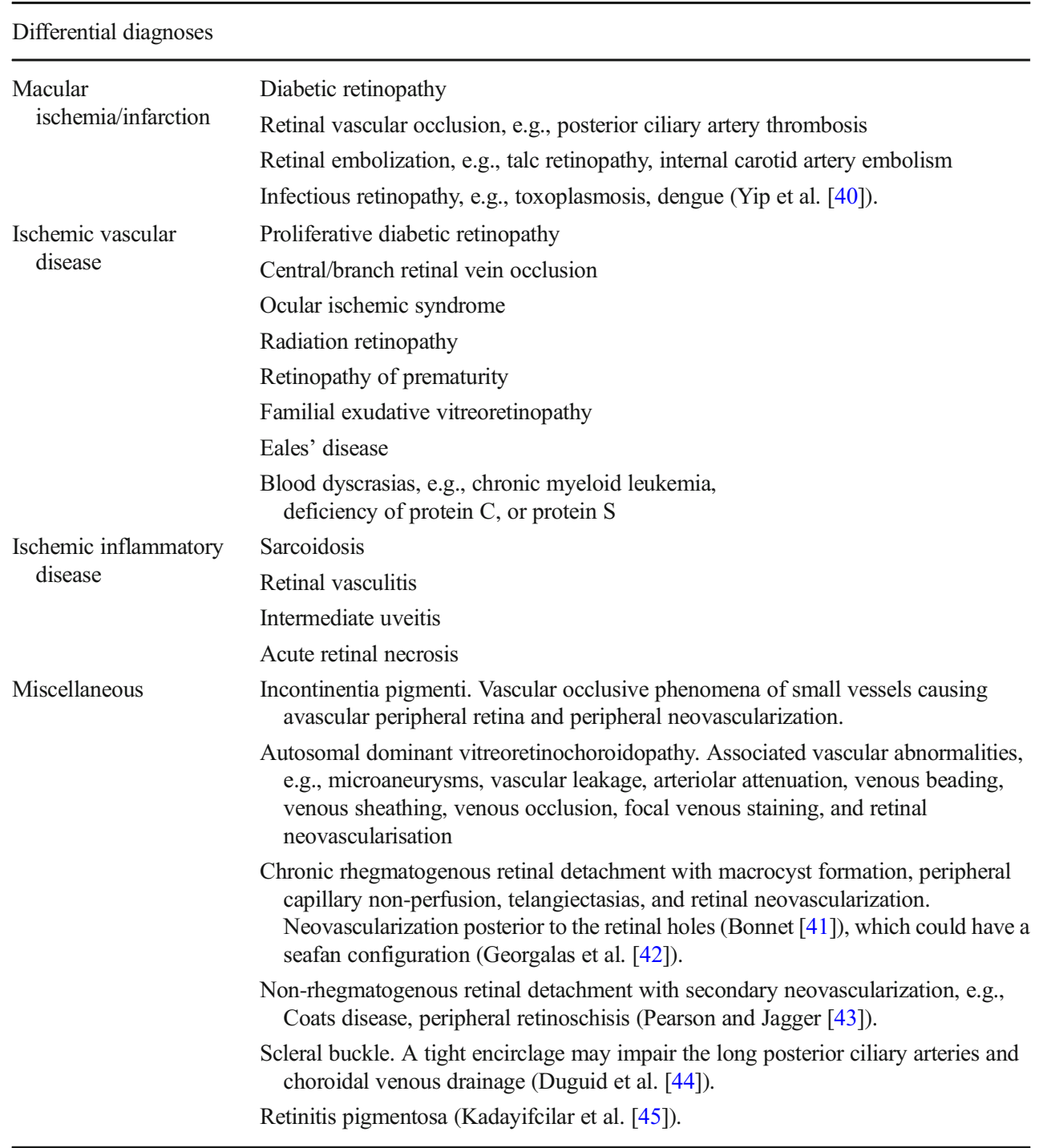

proangiogenic factors may be relevant for proper targeting and delivery of retinal laser treatment. Pigment epithelium derived factor (PEDF) was elevated in HbSC patients with PSR [47]. Increased ICAM-1, VCAM-1, and P-selectin immunoreactivities have also been observed in PSR subjects [48].

\section{Subclinical retinopathy and recent imaging modalities}

Ultra-wide-field fluorescein angiography (UWFA) visualizes vascular abnormalities in the far periphery of the retina, typical of sickle cell retinopathy. Pahl et al. conducted a crosssectional study in pediatric patients (age 10-19 years old) with SCD, demonstrating that all 24 eyes examined by UWFA had sickle cell retinopathy, even if this had not been detected on biomicroscopy. Findings included peripheral arterial occlusion in four of the 24 eyes and peripheral arteriovenous anastomoses in the remaining 20 eyes [49].

In PSR, UWFA may prove to be useful in guiding laser treatment to ischemic areas. Furthermore, by enabling the calculation of an ischemic index based on imaging of the whole retina, a quantitative approach may become possible in the future management of sickle retinopathy $[50,51]$.

Spectral-domain optical coherence tomography and optical coherence tomography angiography (SD-OCT and OCT-A) identified abnormal macular thinning and flow voids in the superficial and deep retinal capillary plexus in $20 \%$ of eyes that had been unobserved by biomicroscopy. These findings suggest that pediatric sickle retinopathy may be more prevalent than previously suspected [49, 52]. Temporal macular thinning caused by paracentral acute middle maculopathy may be the result of occlusions at the level of the deep retinal capillary plexus (Fig. 1) [53-55]. These lesions are not detected by fluorescein angiography. Sickle cell patients with focal 


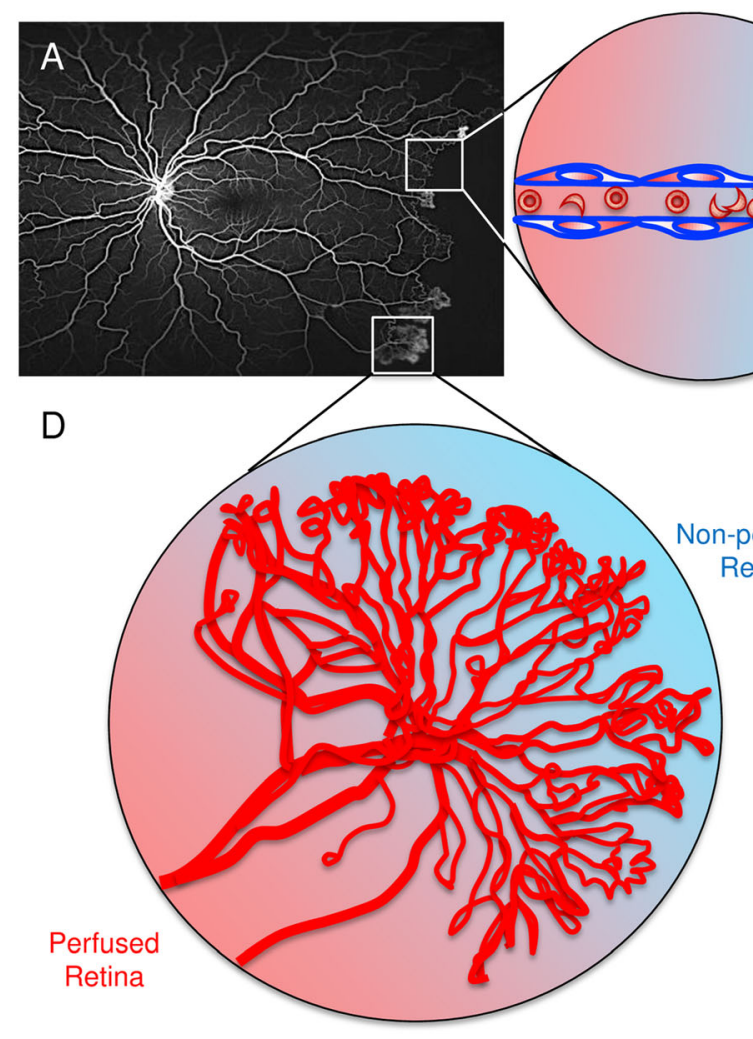

Fig. 2 Figure reprinted from Jee et al. PLoS One 2017 (http://journals. plos.org/plosone/article?id=10.1371/journal. pone.0183320\#pone0183320-g005) courtesy of Dr. Akrit Sodhi, Wilmer Eye Institute [46].

macular thinning identifiable on SD-OCT have significantly decreased retinal function on microperimetry compared with subjects without focal thinning or controls [56]. Such maculopathy may be a marker of PSR and potentially of the severity of SCD.

The development and use of SD-OCT and OCT-A suggest that significant macular vascular changes occur early in the natural history - even in asymptomatic patients. Identification of subclinical retinopathy will help identify those patients who need to be screened.

Thus, further prospective study is warranted, using wide-field imaging, SD-OCT, and OCT-A to determine prognostic markers in sickle retinopathy and optimal laser delivery for PSR.

\section{Prophylactic therapy}

Similar to diabetic retinopathy, systemic management has a significant impact on retinopathy development and progression. $\mathrm{HbF}$ usually disappears from the blood of infants after about 6 months; however, it is found in certain conditions, such as myeliod leukemia and sickle cell crisis. Hydroxycarbamide promotes the production of $\mathrm{HbF}$, which does not polymerize and deform red blood cells like the mutated $\mathrm{HbS}$ and thus has a favorable effect in children in

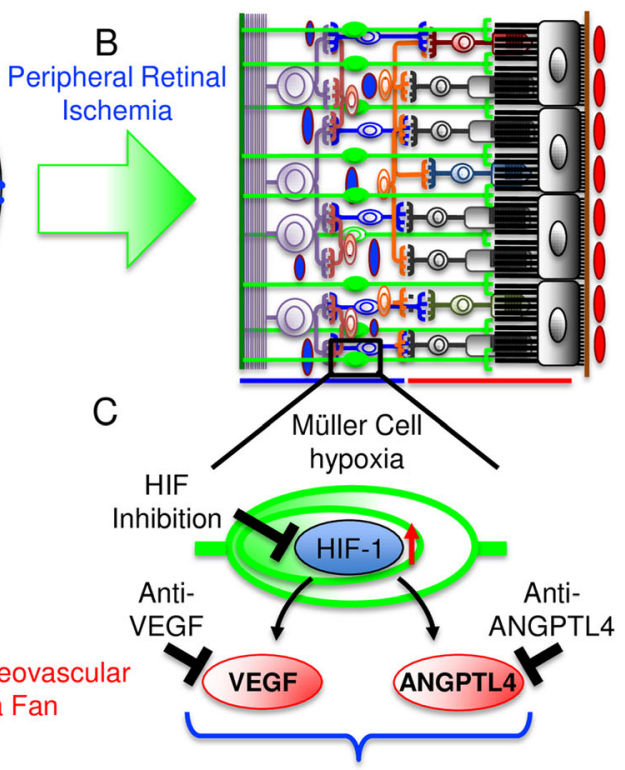

Retinal Vascular Endothelial Cells

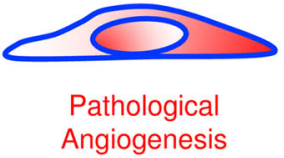

Schematic illustration depicting the progression from peripheral nonperfusion to the development of neovascular sea fans in proliferative sickle retinopathy

preventing retinopathy [57]. In sickle cell hemoglobin therapy, the goal is to dilute the HbS containing erythrocytes to ensure better tissue oxygenation and thus prevent vascular occlusion. Children with a $\mathrm{HbF}<15 \%$ had 7.1-fold higher odds of developing retinopathy, and those with retinopathy had lower $\mathrm{HbF}$ levels compared with children without retinopathy. Likewise, reducing HbSS concentration by exchange transfusion has also been reported to be successful $[58,59]$. Thus, the presence and type of systemic treatment, such as hydroxycarbamide, may need to be taken into account when studying the retinal response to local treatment such as laser. On the other hand, Fox et al. compared hematological indices, such as fetal hemoglobin (HbF) levels, in $33 \mathrm{HbSC}$ patients with progression to PSR and the 17 with regression of PSR and found no significant differences [14]. This implies that the biological mechanism that results in progression towards PSR may be other than just vascular occlusion and ischemia and may in addition require the activation of specific proangiogenic molecules.

Hyperbaric oxygen therapy (HBO) may reverse the pathology and has been described to improve the visual acuity in a patient with central retinal artery occlusion associated with SCD [60]. HBO therapy increases arterial pO2, thereby potentially reversing erythrocyte sickling in the retinal and optic nerve microcirculation. However, a simultaneous exchange 
transfusion was administered, which may on its own have had beneficial effects on the retinopathy through reduction of sickling, thereby confounding a potential effect of the HBO [60]. $\mathrm{HBO}$ administration has also been administered during scleral buckling surgery for RRD associated with $\mathrm{SCD}$, with reportedly favorable outcome [61]. However to date, there have been no prospective controlled studies using HBO in the management of complications associated with sickle cell retinopathy $[60,61]$. A potential cure the hematological disease as such, for example through gene therapy or stem cell transplantation, would prevent retinopathy and could therefore be considered as primary prevention or prophylaxis. Retinal laser therapy or intravitreal anti-angiogenic therapy may be seen as secondary prevention, for example to prevent $\mathrm{VH}$ in the presence of PSR.

\section{Screening}

It was suggested that serial examinations may be done biannually for eyes with normal findings [62]. The development of PSR is believed to be highly unlikely before age 10 years [31]. For example, Rosenberg \& Hutcheson screened 258 pediatric patients with SCD with dilated fundus examination [31]. Of these, 54 (20.9\%) had retinopathy, and $11(4.3 \%)$ had PSR. The average age of patients with any retinopathy was 13.0 years (range, 6-18 years). Patients with PSR were slightly older (mean, 14.18 years; range, $11-17$ years) than those with NPSR (mean, 12.72 years; range, $6-18$ years), but the difference was not statistically significant [31]. Thus, a consensus report (EvidenceBased Management of Sickle Cell Disease Expert Panel Report, 2014: Guide to Recommendations, available on https:// www.nhlbi.nih.gov/sites/default/files/media/docs/Evd-Bsd_ SickleCellDis_Rep2014.pdf accessed on 20190218) stated that annual or biannual screening for retinopathy is recommended from 10 years of age; however, the evidence for this recommendation was evaluated as being of low-quality. The aim of retinopathy screening is to detect PSR and consider treatment for example photocoagulation before complications, such as VH or TRD or retinal vascular occlusions with visual loss occur. In terms of diagnostic screening, DNA screening in newborns at risk, for example with a positive family history of $\mathrm{SCD}$, has been suggested $[38,39]$.

\section{Treatment}

Anemia that may be associated with hemoglobin disorders may require blood transfusions. If so, patients may need therapy with iron chelating agents, to reduce toxicity to multiple organs from iron overload. However, iron chelating therapy may result in maculopathy as a side effect of the medication, possibly related to chelation of other essential trace substances, such as copper and zinc leading to intracellular deficiency of these substances in the retinal pigment epithelium (Fig. 3). However, there may be a direct toxic effect to the RPE from the medication (Fig. 3) [63].

\section{Laser photocoagulation}

Due to the risk of vitreous hemorrhage and retinal detachment, scatter photocoagulation may be considered in order to prevent visual loss and $\mathrm{VH}$ if the sea fans do not autoinfarct (Fig. 1). This is based on two clinical trials $[64,65]$ that were subsequently analyzed in a Cochrane review comprising a total of 341 eyes [66]. The review corroborated that laser treatment may prevent the occurrence of $\mathrm{VH}$, with the protective effect being greater with feeder vessel laser treatment compared with scatter photocoagulation [66]. However, the feeder vessel technique of laser treatment is considered as being potential harmful, sometimes leading to vitreous hemorrhage and retinal breaks and has been abandoned [66]. Moreover, the Cochrane review was based on two studies $[64,65]$ performed in the early 1980 s and 1990 s, thus the results may not apply considering recent development of laser technology [66]. Furthermore, none of the studies used circumferential scatter laser—only limited laser techniques, such as sectorial scatter and feeder vessel photocoagulation. There was no significant difference regarding regression of PSR or rate of development of new PSR, which was the primary outcome, between the treatment and control groups, over a mean follow up duration of 47 and 42 months, respectively [66]. The reason why there was no clear benefit of laser compared with observation in PSR may thus have been related to a lack of consensus regarding how to apply the laser treatment. Recently, the study of autopsy eyes with SCD suggested that hypoxia-inducible factor 1 (HIF-1 $\alpha$ ) and vascular endothelial growth factor (VEGF) are being produced not only in the endothelial cells lining the neovascularizations and in the inner retina of the peripheral non-perfused retina distantly from the neovascularizations but also to some extent in a $2-\mathrm{mm}$ wide transitional zone posterior to the non-perfused periphery [67]. This may support broad application of peripheral laser, such as circumferential scatter covering the entire area from the Ora Serrata anteriorly up to $1-2 \mathrm{~mm}$ posteriorly to the neovascularization for the treatment of PSR [67]. Recent development in wide-field imaging enables targeted laser to ischemic retina, which may be beneficial. However, this has not been examined to date in any prospective trial.

\section{Intravitreal injection of anti-vascular endothelial growth factors}

Current evidence is based on the use of bevacizumab with one exception describing the use of ranibizumab [68]. Similarly to proliferative diabetic retinopathy, intravitreal 

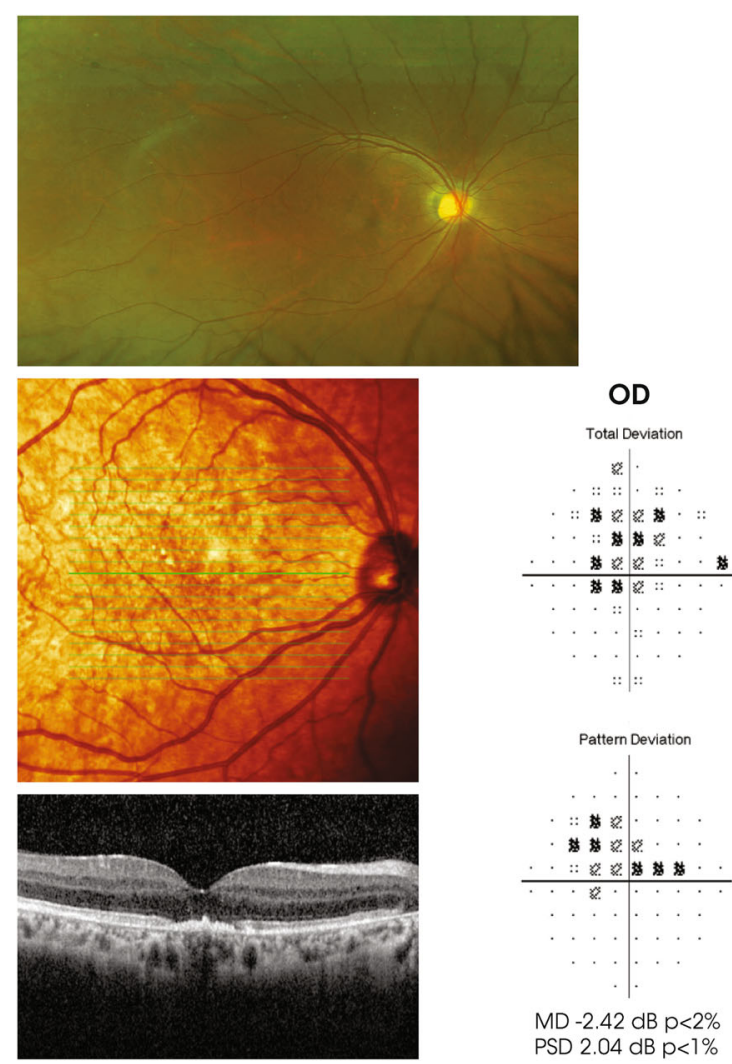

$M D-2.42 \mathrm{~dB} p<2 \%$ PSD $2.04 \mathrm{~dB} p<1 \%$

Fig. 3 A patient with known beta-thalassemia that had received blood transfusions for anemia and iron chelating medication for many years (Desferioxamin and Desferal). Vision was reduced. However, there was no nyctalopia or photophobia. Upper panel: Color fundus images show

administration of bevacizumab therapy may lead to regression of neovascularization. Intravitreal bevacizumab can be used as a pre-surgical adjunctive agent to decrease the risk of intraoperative bleeding and facilitate dissection of sea fan neovascular structures [69-71]. Although preoperative bevacizumab may be efficient, secondary hyphaema, a few days post-injection, is a possible complication [72]. Cai et al. recently described five eyes of five patients with PSR that were managed with intravitreal bevacizumab therapy over a 13-year period [73]. Four patients had HbSC disease and one had HbSthal disease. Four of the patients were treated for recurrent vitreous hemorrhage, and one was treated for new peripheral sea fan neovascularization. The vitreous hemorrhage cleared starting from 2 weeks after the treatment, and all patients showed a partial regression of the neovascularizations. Two of the patients had documented recurrent vitreous hemorrhage during the period of follow-up after an initial injection [73]. Clinical trials directly comparing the effect of intravitreal injections of antiangiogenic agents with scatter laser photocoagulation PSR are warranted.
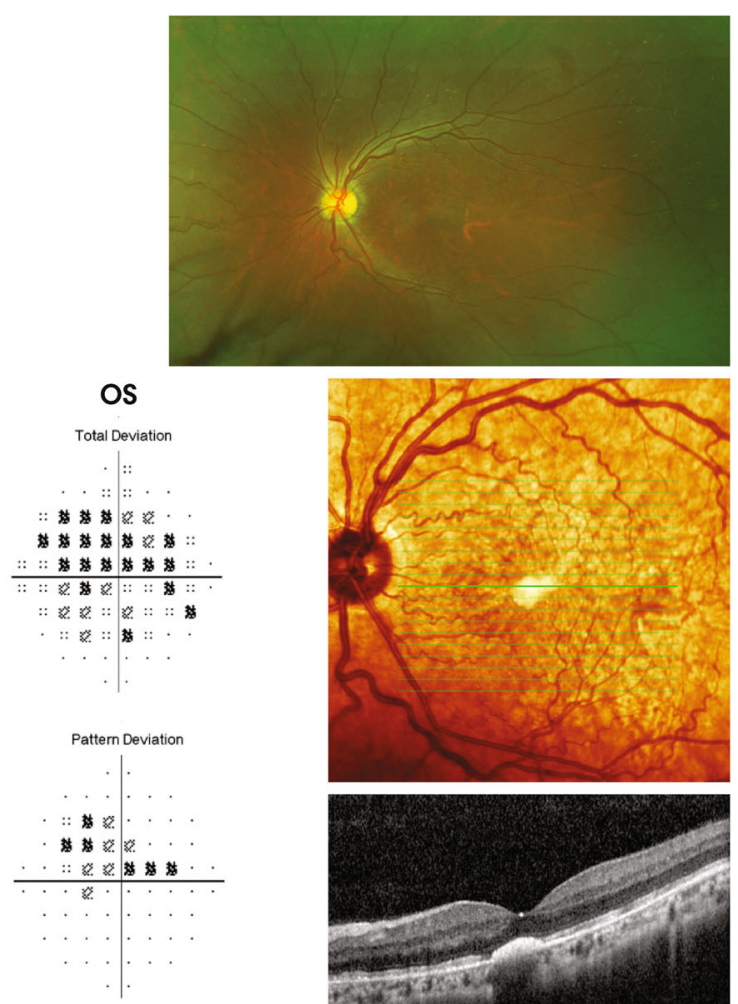

$M D-3.46 \mathrm{~dB} p<1 \%$ PSD $1.67 \mathrm{~dB}$ p $<5 \%$

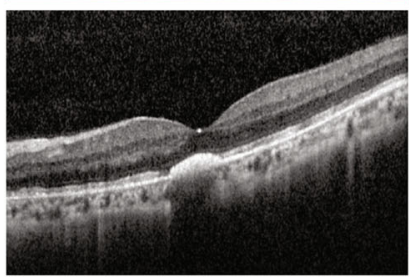

subtle pigment alterations in the maculas. Lower panel, left and right: Optical coherence tomography shows bilateral irregularities and accumulation of material at the level of the retinal pigment epithelium-outer retina complex in the macula. Center: visual field defects are demonstrated

\section{Vitrectomy}

Indications for pars plana vitrectomy (PPV) in PSR are visually significant non-clearing vitreous hemorrhage, bilateral vitreous hemorrhage, vitreous hemorrhage in a monocular patient, or a retinal detachment (Supplemental Fig. 1 and Video 1) [74]. Scleral buckle surgery (SBS) is known to reduce retinal blood flow and alter perfusion of anterior structures, e.g., anterior choroid, ciliary body, and ciliary processes [75]. It has also been implicated in anterior segment ischemia. Therefore, a scleral buckle should not be encircled overly tight in PSR, where there is a compromised perfusion to start with, due to the ischemic nature of the disease.

A retrospective, interventional case series of PSR patients managed with PPV over a 12-year period exhibited success in improving vision postoperatively in patients with vitreous hemorrhage or epiretinal membranes [74]. Nevertheless, there was reduced success in patients with recurrent TRD or RRD. The rate of surgical complications in patients with PSR was as high as 50\% for traction/RRD [74]. Four of the eight patients developed recurrent detachments and required a second operation. All retinas were attached at last follow-up, and visual 
acuity was 20/400 or better in all eyes. No cases of anterior segment ischemia were encountered [74].

Segmentation techniques were recommended over delamination techniques for dissection of peripheral neovascular fibrovascular tissue and epiretinal membranes in PSR [64, 76]. This was because these structures were strongly adherent, and removing them using delamination could risk iatrogenic tears. However with recent improvement of instrumentation and intraoperative OCT, delamination may be feasible (Supplemental Fig. 1 and Video 1).

General anesthesia (GA) would be ideal due to its provided optimal intraoperative pain control; however, this may risk intraoperative systemic sickle cell crisis. A hematological consultation should be obtained before surgery, and patients should be well hydrated and oxygenated in the perioperative period [13]. In cases where GA is contraindicated, sub-Tenon block is preferable to retrobulbar block in SCD patients as such patients have a theoretical risk of orbital compartment syndrome from orbital sickling events [77]. It is essential to minimize prolonged periods of significant rise in IOP during the surgery because of the risk of arterial occlusion.

Hematopoietic stem cell transplantation has the potential to cure SCD as such, including preventing any retinopathy; however, such treatment may be associated with complications including infertility and debilitating graft-versus-host disease and a mortality rate of $5-10 \%$ in the short term $[78,79]$. Gene therapy for hemoglobinopathies has been described in single cases using transplantation of autologous hematopoietic stem cells genetically modified with a lentiviral vector expressing a globin gene under the control of globin transcriptional regulatory elements [80]; however, an altered bone marrow microenvironment that reduces the efficiency of stem cell harvesting as well as engraftment still limits its general application.

\section{Conclusion and further directions}

Recent advances in ocular imaging, such as SD-OCT and OCT-A, have revealed the microstructural features of sickle cell retinopathy, enabling improved diagnostic precision and earlier diagnosis. Maculopathy with inner retinal thinning may be a marker of PSR. The vascular growth factor ANGPTL-4 has been identified as a possible mediator of the progression from NPSR to PSR. Retinal laser therapy for the latter is often administered in order to prevent complications of PSR, such as $\mathrm{VH}$; however, the evidence in favor of laser is not very strong. A more extensive circumferential laser targeting the entire peripheral ischemic retina may be useful; however, such an approach has not been studied in any randomized trials to date. Targeted laser to ischemic retina is possible with the recent development of wide-field imaging. New development of microsurgical vitreoretinal equipment with exact control of intraoperative IOP, including valved trocar vitrectomy systems, may be of benefit in improving the outcomes of surgery for complications associated with PSR. Inhibition of HIF- $1 \alpha$ or both VEGF and ANGPTL- 4 could be an effective approach for the treatment of PSR. Stem cell transplantation and gene therapy are potentially curative treatments under development that may prevent any retinopathy from developing. Whether these advances may lead to improved management and outcomes of treatment of sickle retinopathy remains unanswered, and further study is needed.

Acknowledgments We thank Mr. Adolph Cabanas at Design \& Publication Services at King Khaled Eye Specialist Hospital for their skillful technical assistance. Figure 2 was reprinted from Jee et al. PLoS One 2017 (http://journals.plos.org/plosone/article?id=10.1371/journal. pone.0183320\#pone-0183320-g005) courtesy of Dr. Akrit Sodhi, Wilmer Eye Institute [46].

Author contributions Design of the study (MAE, PS); conduct of the study (MAE, PS); collection, management, analysis, and interpretation of the data (MAE, MM, HD, SS, RM, IK, PS); preparation, review, and final approval of the manuscript (MAE, MM, HD, SS, RM, IK, PS).

Funding information No funding was received for this research.

\section{Compliance with ethical standards}

Conflict of interest All authors certify that they have no affiliations with or involvement in any organization or entity with any financial interest (such as honoraria; educational grants; participation in speakers' bureaus; membership, employment, consultancies, stock ownership, or other equity interest; and expert testimony or patent-licensing arrangements) or non-financial interest (such as personal or professional relationships, affiliations, knowledge or beliefs) in the subject matter or materials discussed in this manuscript.

Ethical approval All procedures performed in studies involving human participants were in accordance with the ethical standards of the institutional and/or national research committee and with the 1964 Helsinki declaration and its later amendments or comparable ethical standards. For this type of study, formal consent is not required. All procedures performed in studies involving animals were in accordance with the ethical standards of the institution or practice at which the study was conducted.

Open Access This article is distributed under the terms of the Creative Commons Attribution 4.0 International License (http:// creativecommons.org/licenses/by/4.0/), which permits unrestricted use, distribution, and reproduction in any medium, provided you give appropriate credit to the original author(s) and the source, provide a link to the Creative Commons license, and indicate if changes were made.

\section{References}

1. Jastaniah W (2011) Epidemiology of sickle cell disease in Saudi Arabia. Ann Saudi Med 31:289-293

2. Makani J, Williams TN, Marsh K (2007) Sickle cell disease in Africa: burden and research priorities. Ann Trop Med Parasitol 101:3-14

3. Goldberg MF (1979) The diagnosis and treatment of secondary glaucoma after hyphema in sickle cell patients. Am J Ophthalmol 87:43-49 
4. Sayag D, Binaghi M, Souied EH et al (2008) Retinal photocoagulation for proliferative sickle cell retinopathy: a prospective clinical trial with new sea fan classification. Eur J Ophthalmol 18:248-254

5. Condon PI, Serjeant GR (1972) Ocular findings in hemoglobin SC disease in Jamaica. Am J Ophthalmol 74:921-931

6. Fox PD, Dunn DT, Morris JS, Serjeant GR (1990) Risk factors for proliferative sickle retinopathy. Br J Ophthalmol 74:172-176

7. Fekrat S, Goldberg MF (1998) Sickle retinopathy. Thieme Medical Publishers, New York

8. Dembélé AK, Toure BA, Sarro YS et al (2017) Prevalence and risk factors for sickle retinopathy in a sub-Saharan comprehensive sickle cell center. Rev Med Interne 38:572-577

9. Bonanomi MT, Cunha SL, de Araújo JT (1988) Funduscopic alterations in SS and SC hemoglobinopathies. Study of a Brazilian population. Ophthalmologica 197:26-33

10. Leveziel N, Lalloum F, Bastuji-Garin S et al (2012) Rétinopathie drépanocytaire : analyse rétrospective portant sur 730 patients suivis dans un centre de référence. [Sickle-cell retinopathy: retrospective study of 730 patients followed in a referral center]. J Fr Ophtalmol 35:343-347

11. Downes SM, Hambleton IR, Chuang EL et al (2005) Incidence and natural history of proliferative sickle cell retinopathy: observations from a cohort study. Ophthalmology 112:1869-1875

12. Hayes RJ, Condon PI, Serjeant GR (1981) Haematological factors associated with proliferative retinopathy in sickle cell-haemoglobin C disease. Br J Ophthalmol 65:712-717

13. Chen RW, Flynn HW, Fekrat S, Goldberg MF (2018) Sickle retinopathy. In: Scott IU, Regillo CD, Flynn HW, Brown GC (eds) Vitreoretinal disease. Diagnosis management and clinical pearls. Thieme Publishers, New York, pp 313-323

14. Fox PD, Vessey SJ, Forshaw ML, Serjeant GR (1991) Influence of genotype on the natural history of untreated proliferative sickle retinopathy-an angiographic study. Br J Ophthalmol 75:229-231

15. Cusick M, Toma HS, Hwang TS et al (2007) Binasal visual field defects from simultaneous bilateral retinal infarctions in sickle cell disease. Am J Ophthalmol 143:893-896

16. Bottin C, Racine J, Robert MP et al (2017) Electroretinogram findings in early-stage sickle cell retinopathy according to hemoglobin type. Invest Ophthalmol Vis Sci 58:3262-3267

17. Moriarty BJ, Acheson RW, Condon PI, Serjeant GR (1988) Patterns of visual loss in untreated sickle cell retinopathy. Eye (Lond) 2:330-335

18. Scott AW (2016) Ophthalmic manifestations of sickle cell disease. South Med J 109:542-548

19. Murthy RK, Grover S, Chalam KV (2011) Temporal macular thinning on spectral-domain optical coherence tomography in proliferative sickle cell retinopathy. Arch Ophthalmol 129:247-249

20. Brasileiro F, Martins TT, Campos SB et al (2015) Macular and peripapillary spectral domain optical coherence tomography changes in sickle cell retinopathy. Retina 35:257-263

21. Alsuhaibani AH, Marzouk MA (2011) Recurrent infarction of sphenoid bone with subperiosteal collection in a child with sickle cell disease. Ophthal Plast Reconstr Surg 27:136-138

22. Helen OO, Ajite KO, Oyelami OA et al (2013) Bilateral orbital infarction and retinal detachment in a previously undiagnosed sickle cell hemoglobinopathy in an African child. Niger Med J 54:200-202

23. Brandow AM, Liem R (2011) Sickle cell disease in the emergency department: atypical complications and management. Clin Pediatr Emerg Med 12:202-202

24. Ferrão TO, Martins-Filho PR, Aragão C et al (2017) Doppler velocimetry of the orbital arteries in patients with sickle cell anemia: relationship with biomarkers of hemolysis. Radiol Bras 50: 103-108

25. Goldberg MF (1971) Classification and pathogenesis of proliferative sickle retinopathy. Am J Ophthalmol 71:649-665
26. Elguero E, Délicat-Loembet LM, Rougeron V et al (2015) Malaria continues to select for sickle cell trait in Central Africa. Proc Natl Acad Sci U S A 112:7051-7054

27. Serjeant BE, Mason KP, Condon PI et al (1984) Blood rheology and proliferative retinopathy in sickle cell-haemoglobin $\mathrm{C}$ disease. Br J Ophthalmol 68:325-328

28. Clarkson JG (1992) The ocular manifestations of sickle cell disease: a prevalence and natural history study. Tr Am Ophth Soc 90:481504

29. Al Harbi M, Khandekar R, Kozak I, Schatz P (2016) Association between sickle cell trait and the prevalence and severity of diabetic retinopathy. PLoS One 11:e0159215

30. Talbot JF, Bird AC, Maude GH et al (1988) Sickle cell retinopathy in Jamaican children: further observations from a cohort study. Br J Ophthalmol 72:727-732

31. Rosenberg JB, Hutcheson KA (2011) Pediatric sickle cell retinopathy: correlation with clinical factors. JAAPOS 15:49-53

32. Saidkasimova S, Shalchi Z, Mahroo OA et al (2016) Risk factors for visual impairment in patients with sickle cell disease in London. Eur J Ophthalmol 26:431-435

33. Duan XJ, Lanzkron S, Linz MO, Ewing C, Wang J, Scott AW (2019) Clinical and ophthalmic factors associated with the severity of sickle cell retinopathy. Am J Ophthalmol 197:105-113

34. Vicari P, Adegoke SA, Mazzotti DR et al (2015) Interleukin-1 $\beta$ and interleukin-6 gene polymorphisms are associated with manifestations of sickle cell anemia. Blood Cells Mol Dis 54:244-249

35. Armenis I, Kalotychou V, Tzanetea R et al (2017) Prognostic value of T786C and G894T eNOS polymorphisms in sickle cell disease. Nitric Oxide 62:17-23

36. Mehta JS, Whittaker KW, Tsaloumas MD (2001) Latent proliferative sickle cell retinopathy in sickle cell trait. Acta Ophthalmol Scand 79:81-82

37. Clarke GM, Higgins TN (2000) Laboratory investigation of haemoglobinopathies and thalassemias: review and update. Clin Chem 46:1284-1290

38. Murad H, Moassas F, Jarjour R et al (2014) Prenatal molecular diagnosis of $\beta$-thalassemia and sickle cell anemia in the Syrian population. Hemoglobin 38:390-393

39. Jinks DC, Minter M, Tarver DA et al (1989) Molecular genetic diagnosis of sickle cell disease using dried blood specimens on blotters used for newborn screening. Hum Genet 81:363-366

40. Yip V, Sanjay S, Koh YT (2012) Ophthalmic complications of dengue fever: a systematic review. Ophthalmol Therapy. https:// doi.org/10.1007/s40123-012-0002-z

41. Bonnet M (1987) Peripheral neovascularization complicating rhegmatogenous retinal detachments of long duration. Graefes Arch Clin Exp Ophthalmol 225:59-62

42. Georgalas I, Paraskevopoulos T, Symmeonidis C et al (2014) Peripheral sea-fan retinal neovascularization as a manifestation of chronic rhegmatogenous retinal detachment and surgical management. BMC Ophthalmol 14:112

43. Pearson R, Jagger J (1989) Sex linked juvenile retinoschisis with optic disc and peripheral retinal neovascularization. Br J Ophthalmol 73:311-313

44. Duguid IG, McHugh JD, Blach RK (1995) Peripheral retinal neovascularisation associated with scleral encirclement. Br J Ophthalmol 79:861-862

45. Kadayifçilar S, Eldem B, Kiratli H (2000) Retinitis pigmentosa associated with peripheral sea fan neovascularization. Acta Ophthalmol Scand 78:593-595

46. Jee K, Rodrigues M, Kashiwabuchi F et al (2017) Expression of the angiogenic mediator, angiopoietin-like 4 , in the eyes of patients with proliferative sickle retinopathy. PLoS One 12:e0183320

47. Cruz PR, Lira RP, Pereira Filho SA et al (2015) Increased circulating PEDF and low sICAM-1 are associated with sickle cell retinopathy. Blood Cells Mol Dis 54:33-37 
48. Kunz Mathews M, McLeod DS, Merges C et al (2002) Neutrophils and leucocyte adhesion molecules in sickle cell retinopathy. Br J Ophthalmol 86:684-690

49. Pahl DA, Green NS, Bhatia M et al (2017) Optical coherence tomography angiography and ultra-wide field fluorescein angiography for early detection of adolescent sickle retinopathy. Am J Ophthalmol 183:91-98

50. Tan CS, Chew MC, van Hemert J et al (2016) Measuring the precise area of peripheral retinal non-perfusion using ultra-wide field imaging and its correlation with the ischaemic index. $\mathrm{Br} \mathrm{J}$ Ophthalmol 100:235-239

51. Tsui I, Williams BK Jr, Kok YO et al (2015) Reliability of ischemic index grading in common retinal vascular diseases. Ophthalmic Surg Lasers Imaging Retina 46:618-625

52. Martin GC, Albuisson E, Brousse V, de Montalembert M, Bremond-Gignac D, Robert MP (2018) Paramacular temporal atrophy in sickle cell disease occurs early in childhood. Br J Ophthalmol

53. Hussnain SA, Coady PA, Stoessel KM (2016) BMJ Case Rep doi: https://doi.org/10.1136/bcr-2016-216124

54. Ilginis T, Keane PA, Tufail A (2015) Paracentral acute middle maculopathy in sickle cell disease. JAMA Ophthalmol 133:614-616

55. Sanfilippo CJ, Klufas MA, Sarraf D, Tsui I (2015) Optical coherence tomography angiography of sickle cell maculopathy. Retin Cases Brief Rep 9:360-362

56. Chow CC, Genead MA, Anastasakis A et al (2011) Structural and functional correlation in sickle cell retinopathy using spectraldomain optical coherence tomography and scanning laser ophthalmoscope microperimetry. American J Ophthalmol 152:704-711

57. Estepp JH, Smeltzer MP, Wang WC et al (2013) Protection from sickle cell retinopathy is associated with elevated $\mathrm{HbF}$ levels and hydroxycarbamide use in children. Br J Haematol 161:402-405

58. McKinney CM, Siringo F, Olson JL et al (2015) Red cell exchange transfusion halts progressive proliferative sickle cell retinopathy in a teenaged patient with hemoglobin SC disease. Pediatr Blood Cancer 62:721-723

59. Mian UK, Tang J, Allende APM, Heo M, Bernstein N, Vattappally L, Schoenfeld D, Minniti CP (2018) Elevated fetal haemoglobin levels are associated with decreased incidence of retinopathy in adults with sickle cell disease. Br J Haematol 183:807-811

60. Canan H, Ulas B, Altan-Yaycioglu R (2014) Hyperbaric oxygen therapy in combination with systemic treatment of sickle cell disease presenting as central retinal artery occlusion: a case report. J Med Case Rep 8:370

61. Freilich DB, Seelenfreund MH (1972) The use of hyperbaric oxygen in the treatment of retinal detachment in patients with sickle cell disease. Isr J Med Sci 8:1458-1461

62. Gill HS, Lam WC (2008) A screening strategy for the detection of sickle cell retinopathy in pediatric patients. Can J Ophthalmol 43: 188-191

63. Klettner A, Koinzer S, Waetzig V, Herdegen T, Roider J (2010) Deferoxamine mesylate is toxic for retinal pigment epithelium cells in vitro, and its toxicity is mediated by p38. Cutan Ocul Toxicol 29: $122-129$

64. Jampol LM, Condon P, Farber M et al (1983) A randomized clinical trial of feeder vessel photocoagulation of proliferative sickle cell retinopathy. I. Preliminary results. Ophthalmology 90:540-545
65. Rednam KR, Jampol LM, Goldberg MF (1982) Scatter retinal photocoagulation for proliferative sickle cell retinopathy. Am J Ophthalmol 93:594-599

66. Myint KT, Sahoo S, Thein AW et al (2015) Laser therapy for retinopathy in sickle cell disease. The Cochrane Database of Systematic Reviews. https://doi.org/10.1102/14651858.CD010790

67. Rodrigues M, Kashiwabuchi F, Deshpande M et al (2016) Expression pattern of HIF-1 $\alpha$ and VEGF supports circumferential application of scatter laser for proliferative sickle retinopathy. Invest Ophthalmol Vis Sci 57:6739-6746

68. Mitropoulos PG, Chatziralli IP, Parikakis EA et al (2014) Intravitreal ranibizumab for stage IV proliferative sickle cell retinopathy: a first case report. Case reports in Ophthalmological Medicine 2014:682583

69. Guthrie G, Hall AB, Dhalla K et al (2013) Bevacizumab as an adjunct to vitreoretinal surgery for diabetic retinopathy in East Africa. Eye (Lond) 27:1263-1268

70. Pokroy R, Desai UR, Du E et al (2011) Bevacizumab prior to vitrectomy for diabetic traction retinal detachment. Eye (Lond) 25:989-997

71. Moshiri A, Ha NK, Ko FS, Scott AW (2013) Bevacizumab presurgical treatment for proliferative sickle-cell retinopathy-related retinal detachment. Retinal Cases \& Brief Reports 7:204-205

72. Babalola OE (2010) Intravitreal bevacizumab (Avastin) associated with secondary hyphaema in a case of proliferative sickle cell retinopathy. BMJ Case Rep. https://doi.org/10.1136/bcr.11.2009.2441

73. Cai CX, Linz MO, Scott AW (2018) Intravitreal bevacizumab for proliferative sickle retinopathy: a case series. Journal of VitreoRetinal Diseases 2:32-38

74. Chen RW, Flynn HW Jr, Lee WH et al (2014) Vitreoretinal management and surgical outcomes in proliferative sickle retinopathy: a case series. Am J Ophthalmol 157:870-875

75. Schwartz SG, Flynn HW (2006) Primary retinal detachment: scleral buckle or pars plana vitrectomy? Curr Opin Ophthalmol 17:245-250

76. Williamson TH, Rajput R, Laidlaw DAH, Mokete B (2009) Vitreoretinal management of the complications of sickle cell retinopathy by observation or pars plana vitrectomy. Eye (Lond) 23: 1314-1320

77. Curran EL, Fleming JC, Rice K, Wang WC (1997) Orbital compression syndrome in sickle cell disease. Ophthalmology 104: $1610-1615$

78. King A, Shenoy S (2014) Evidence-based focused review of the status of hematopoietic stem cell transplantation as treatment of sickle cell disease and thalassemia. Blood 123:3089-3094

79. Fitzhugh CD, Walters MC (2017) The case for HLA-identical sibling hematopoietic stem cell transplantation in children with symptomatic sickle cell anemia. Blood Adv 1:2563-2567

80. Ferrari G, Cavazzana M, Mavilio F (2017) Gene therapy approaches to hemoglobinopathies. Hematol Oncol Clin North Am $31: 835-852$

Publisher's note Springer Nature remains neutral with regard to jurisdictional claims in published maps and institutional affiliations. 